\title{
Influence of Physiological Variability on Thermal Comfort: A Numerical Evaluation
}

\author{
E. Walther ${ }^{1}$, A. K. Mishra ${ }^{2}$, V. Forcadell ${ }^{3}$ \\ ${ }^{1}$ AREP, Paris (France) \\ ${ }^{2}$ Berkeley Education Alliance for Research in Singapore Limited (Singapore) \\ ${ }^{3}$ ENS Paris-Saclay, Cachan (France)
}

\begin{abstract}
Thermal comfort indexes based on physiological models are generally based on the morphology of an average, male individual. The present work explores the effects of physiological variability on the calculation of thermal comfort using the Standard Effective Temperature $\left(\mathrm{SET}^{*}\right)$. A semi-probabilistic approach is used for the study, with French population demographics as input. Parameters in the physiological model behind the SET ${ }^{*}$ index that vary with human physiology were generated according to probabilistic laws and data from the literature.

The results demonstrate that the temperature acceptability range determined by the model is exceeded for this population. However, standard deviations obtained proved to be relatively low compared to field data from literature. A sensitivity analysis showed that the most influential parameters of the model are sex, age, height and BMI.
\end{abstract}

\section{Introduction}

The SET* comfort index is based on the "two-node model" of human thermoregulatory system Gagge et al. (1971) and usable for both indoors or outdoors Pickup et al. (2000). Under given environmental conditions, the model yields thermal comfort indicators, such as core temperature, skin temperature and skin wettedness. In steady state, for near sedentary occupants, the two-nodel model is known to yield reasonably accurate estimates for skin and core temperature Doherty and Arens (1988); Takada et al. (2011). It uses heat and mass balance equations, human thermoregulatory functions, and the following six environmental and personal parameters:

- Air temperature $T_{a}$ : convective heat transfer

- Mean radiant temperature $T_{r}$ : radiative transfer

- Air velocity $v$ : convective and evaporative heat transfer

- Relative humidity $R H$ : evaporative heat transfer

- Clothing insulation [clo]: resistance to heat loss

- Individual metabolic rate [met]: generated body heat
For long, the SET* thermal comfort index has been associated with the two-node model. By definition, SET $^{*}$ is "the temperature of an imaginary environment at $50 \%$ relative humidity, $<0.1 \mathrm{~m} / \mathrm{s}$ average air speed, and mean radiant temperature equal to average air temperature, in which total heat loss from the skin of an imaginary occupant with an activity level of 1.0 met and a clothing level of 0.6 clo is the same as that from a person in the actual environment, with actual clothing and activity level" ASHRAE (2013), resembling the conditions of a typical indoor.

Earlier works have looked at how a comfort model's physiological parameters may be adapted to individual physiology, fitting measured body temperatures Zhou et al. (2014). A more recent study explored how including individual's physiological parameters can improve a model's predictive ability for a group of human subjects Davoodi et al. (2018). This work addresses how physiological parameter variability across a population affects the evaluation of SET*, in the spirit of Bruse (2007), thus giving an estimation of individual thermal comfort needs.

Translating from the comfort requirements as specified from the PMV-PPD model for sedentary office workers, the comfortable SET ${ }^{*}$ values range from 22.2 to $25.6^{\circ} \mathrm{C}$ (a mere conversion from the $72-78^{\circ} \mathrm{F}$ range from ASHRAE 55-74) Nishi and Gagge (1977). In order to verify this comfort range for a given population, Monte-Carlo simulations were led using sets of physiological parameters following aleatory distributions around the physiological values garnered from literature.

\section{Two-node model}

We briefly present here the two-node heat balance model and the integration of physiological variability.

\section{Heat balance equations}

Considering the human body as a cylinder, the core and skin temperatures $T_{c}$ and $T_{\mathrm{s}}$ may be derived using heat balance equations of the core and skin 
nodes ASHRAE (2009):

$$
\begin{aligned}
\alpha \frac{m c_{p}}{A} \frac{d T_{\mathrm{c}}}{d t} & =M-U_{\mathrm{T}} \times\left(T_{\mathrm{c}}-T_{\mathrm{s}}\right)-Q_{\mathrm{r}}(1) \\
(1-\alpha) \frac{m c_{p}}{A} \frac{d T_{\mathrm{s}}}{d t} & =U_{\mathrm{T}} \times\left(T_{\mathrm{c}}-T_{\mathrm{s}}\right)-H-E(2)
\end{aligned}
$$

where $M$ is the metabolic rate $\left[\mathrm{W} . \mathrm{m}^{-2}\right], A$ the body heat exchange surface area $\left[\mathrm{m}^{2}\right], m$ the body mass $[\mathrm{kg}], Q_{\mathrm{r}}$ the total respiratory heat loss $\left[\mathrm{W} \cdot \mathrm{m}^{-2}\right], H$ the sum of convective and radiative losses $\left[\mathrm{W} . \mathrm{m}^{-2}\right]$, $E$ the evaporative heat loss at skin surface: diffusion plus sweating $\left[\mathrm{W} \cdot \mathrm{m}^{-2}\right], \alpha$ the skin mass fraction of total body mass and $\mathrm{U}_{\mathrm{T}}=\mathrm{U}_{\mathrm{c}-\mathrm{sk}}+\dot{\mathrm{m}}_{\mathrm{b}} \mathrm{c}_{\mathrm{b}}$ the two-node model's total conductance $\left[\mathrm{W} \cdot \mathrm{m}^{-2} \cdot \mathrm{K}^{-1}\right]$, including tissue conductance and heat transfer via specific blood flow $\dot{m}_{b}\left[\mathrm{~kg} \cdot \mathrm{m}^{-2} \cdot \mathrm{s}^{-1}\right]$.

Herein, skin blood flow has been defined as the skin blood flow on body surface $q_{\mathrm{b}}\left[\mathrm{L} \cdot \mathrm{m}^{-2} \cdot \mathrm{h}^{-1}\right]$, where $\dot{\mathrm{m}}_{\mathrm{b}}=\frac{\rho_{\mathrm{b}} / 1000}{3600} \times \mathrm{q}_{\mathrm{b}}$.

\section{Body surface area and metabolic rate}

The Dubois equation was used to determine body heat exchange surface area, based on a person's height (in meters) and mass (in $\mathrm{kg}$ ):

$$
A=0.203 \times m^{0.425} \times h^{0.725} \quad\left[\mathrm{~m}^{2}\right]
$$

Individuals' basal metabolic activity, $\mathrm{M}\left[\mathrm{W} . \mathrm{m}^{-2}\right]$ was computed from the equation for resting energy expenditure Mifflin et al. (1990):

$M=(10 \times m+6.25 \times h \times 100-5 \times a g e+c) \times \frac{4184}{3600 \times 24 A}$

where $c=5$ for men and $c=-161$ for women.

\section{Thermoregulatory model}

For mathematical tractability, thermophysiological models, including the two-node model, represent the human body as a regulated thermal system, with vasoregulation, sweating, and shivering actions triggered by deviations of body temperature from the set-points. The thermoregulatory constants $C_{\mathrm{d}}$ and $C_{\text {st }}$ influence blood flow rate $q_{b}$ :

$$
q_{\mathrm{b}}=\frac{q_{\mathrm{b}}^{\mathrm{set}}+C_{d}\left(T_{\mathrm{c}}-T_{\mathrm{c}}^{\mathrm{set}}\right)}{1+C_{s t}\left(T_{\mathrm{s}}^{\mathrm{set}}-T_{\mathrm{s}}\right)} \quad\left[\mathrm{L} \cdot \mathrm{m}^{-2} \cdot \mathrm{h}^{-1}\right]
$$

where $C_{\mathrm{d}}\left[\mathrm{L} \cdot \mathrm{m}^{-2} \cdot \mathrm{h}^{-1} \cdot \mathrm{K}^{-1}\right]$ and $C_{s}\left[\mathrm{~K}^{-1}\right]$ are the dilation and constriction constants, $q_{\mathrm{b}}^{\text {set }}$ the set (default) blood flow rate $\left[\mathrm{L} \cdot \mathrm{m}^{-2} \cdot \mathrm{h}^{-1}\right], T_{c}$ and $T_{s}$ the core and skin temperatures $\left[{ }^{\circ} \mathrm{C}\right]$, and $T_{c}{ }^{\text {set }}, T_{s}{ }^{\text {set }}$ the core and skin set-point temperatures $\left[{ }^{\circ} \mathrm{C}\right]$. Sweating thermoregulation is governed as:

$$
\dot{m}_{\mathrm{sw}}=C_{\mathrm{sw}} \times\left(T_{\mathrm{b}}-T_{\mathrm{b}}^{\mathrm{set}}\right) \times e^{\frac{\left(T_{\mathrm{s}}-T_{\mathrm{s}}^{\mathrm{set}}\right)}{10.7}} \quad\left[\mathrm{~g} \cdot \mathrm{m}^{-2} \cdot \mathrm{h}^{-1}\right]
$$

where $C_{\mathrm{sw}}$ is the sweating coefficient $\left[\mathrm{g} \cdot \mathrm{m}^{-2} \cdot \mathrm{h}^{-1}\right]$.

For cold environments, shivering allows for internal heat generation $M_{\mathrm{sh}}\left[\mathrm{W} \cdot \mathrm{m}^{-2}\right]$, additional to metabolic activity $M\left[\mathrm{~W} \cdot \mathrm{m}^{-2}\right]$, acting as a cold defence mechanism:

$$
\mathrm{M}_{\mathrm{sh}}=\mathrm{C}_{\mathrm{sh}} \times\left(\mathrm{T}_{\mathrm{s}}^{\mathrm{set}}-\mathrm{T}_{\mathrm{s}}\right)\left(\mathrm{T}_{\mathrm{c}}^{\mathrm{set}}-\mathrm{T}_{\mathrm{c}}\right)
$$

where $C_{\mathrm{sh}}$ is the shivering coefficient $\left[\mathrm{W} \cdot \mathrm{m}^{-2} \cdot \mathrm{K}^{-2}\right]$.

Body specific heat capacity $\left(c_{b}\right)$ varies, with skin mass fraction and specific heat capacities of fat and body tissues (respectively $\mathrm{c}_{\mathrm{f}}=2510\left[\mathrm{~J} \cdot \mathrm{kg}^{-1} \cdot \mathrm{K}^{-1}\right]$ and $\left.c_{\mathrm{t}}=3650\left[\mathrm{~J} \cdot \mathrm{kg}^{-1} \cdot \mathrm{K}^{-1}\right]\right)$ :

$$
c_{b}=\beta \times c_{f}+(1-\beta) \times c_{t}
$$

where $\beta$ is the body fat percentage [\%].

\section{Random sampling of parameters}

The model inputs affected by physiological variations are divided into "primary parameters", directly taken from the literature and "secondary parameters", computed from the primary ones.

\section{Primary parameters}

These parameters are directly affected by physiological variations: sex (as assigned at birth), age, height $h$, body mass index and the core and skin set-point temperatures, respectively $T_{c}^{\text {set }}, T_{s}^{\text {set }}$. When parameters exhibit a Gaussian distribution, they are defined by $(\mu, \sigma)$, respectively their mean value and standard deviation.

\section{Height ( $h$ )}

Height follows a normal distribution, as observed in Duclos et al. (2011); Koepke et al. (2018). The average value and the standard deviation for height were taken from the French national campaign de Saint Pol (2007): $(\mu, \sigma)=(1.63,0.09)[\mathrm{m}]$ for women and $(\mu, \sigma)=(1.75,0.10)[\mathrm{m}]$ for men. An overview of height distribution by sex for 10000 individuals is given in Figure $1 \mathrm{~b}$ ).

Body Mass Index (BMI)

The actual BMI among French taken in de Saint Pol (2007) was best matched by a Weibull distribution, defined by Eqn. (9):

$$
p\left(x, k, n, x_{0}\right)=\frac{k}{n}\left(\frac{x-x_{0}}{n}\right)^{k-1} e^{-\left(\frac{x-x_{0}}{n}\right)^{k}}
$$

The form and scale parameters $(k, n)$ were determined using logarithmic regression on the data. $x_{0}$ was fixed to $x_{0}=\mathrm{BMI}_{0}=16\left[\mathrm{~kg} \cdot \mathrm{m}^{-2}\right]$. Both female and male BMI distributions are shown in Figure $1 \mathrm{c}$ ). To the best of the authors' knowledge, the French age-wise BMI distribution is not available in the literature. The hypothesis was made that the BMI distribution is the same for different age groups.

Age distribution (age)

The age distribution from the 2018 official French census de Saint Pol (2007) is shown in Figure 1 a). Given 

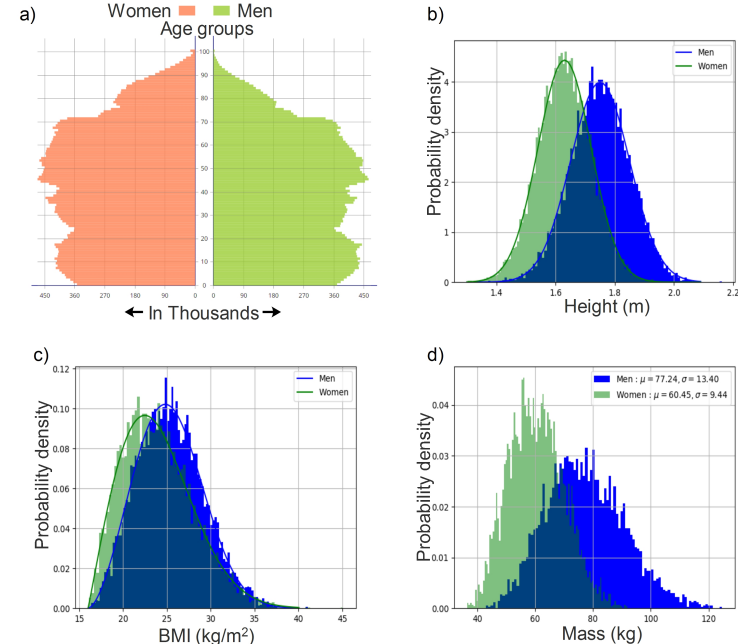

Figure 1: Population characteristics a) French pyramid of ages in thousands per year of age from de Saint Pol (2007), Distributions of b) Height c) $B M I$ d) Mass $(n=10000)$.

the Deurenberg Equation (11) is applicable only between 18 and 65 years, variability was not studied beyond this age range.

Set-point temperatures ( $T_{s}^{\text {set }}$ and $T_{c}^{\text {set }}$ )

The experiment of Chudecka et al. (2014) reports skin temperature as being normally distributed. In Gagge's original model, $T_{s}^{\text {set }}$ and $T_{c}^{\text {set }}$ are respectively $33.7^{\circ} \mathrm{C}$ and $36.8^{\circ} \mathrm{C}$ while other references quote slightly different values Gagge et al. (1971); ASHRAE (2013). Standard deviation was taken as $0.337[\mathrm{~K}]$ for $T_{s}^{\text {set }}$ in order to respect the temperature criteria of Mackowiak et al. (1992) and $0.166[\mathrm{~K}]$ for $T_{c}^{\text {set }}$ so as to remain within $1^{\circ} \mathrm{C}$ of variation for the core set temperature for $99 \%$ of the Gaussian distribution.

\section{Secondary parameters}

Secondary physiological parameters such as mass $m$, body fat percentage $\beta$, mean skinfold thickness $\bar{e}_{s k}$ and tissue conductance $U_{c-s k}$ were derived from the primary parameters. The evaluation of model parameters $C_{d}, C_{s t}, C_{s w}, C_{s h}$ and $q_{b}^{s e t}$ is also possible using primary parameters.

Mass

Mass $m[\mathrm{~kg}]$ is derived from the BMI and height :

$$
B M I=\frac{m}{h^{2}}
$$

BMI is a consistent indicator of body morphology when within $17<$ BMI $<32\left[\mathrm{~kg} . \mathrm{m}^{-2}\right]$ and hence was not used without these bounds.

The obtained average mass for men and women was respectively $60.5[\mathrm{~kg}]$ and $77.2[\mathrm{~kg}]$ (Figure $1 \mathrm{~d}$ ), which compares well with the values given by the national statistical institute de Saint Pol (2007): $\mu=63$ [kg] for women and $\mu=77[\mathrm{~kg}]$ for men.

Body fat percentage $(\beta)$
Correlations between body fat percentage $\beta[\%]$ and BMI $\left[\mathrm{kg} . \mathrm{m}^{-2}\right]$ have been derived for different population groups Pasco et al. (2012); Ranasinghe et al. (2013). In absence of a specific correlation for the French, the formula by Deurenberg et al. (1991) appeared to be the most appropriate:

$$
\beta=1.2 \times \mathrm{BMI}+0.23 \times \text { age }-10.8 \times \operatorname{sex}-5.4[\%]
$$

Body tissues conductance $\left(U_{c-s k}\right)$ and mean skinfold thickness $\left(\overline{\mathrm{e}_{\mathrm{sk}}}\right)$

Body tissues conductance $\mathrm{U}_{\mathrm{c} \text {-sk }}$ in the Gagge model is constant at $\mathrm{U}_{\mathrm{c}-\mathrm{sk}}=5.28\left[\mathrm{~W} \cdot \mathrm{m}^{-2} \cdot \mathrm{K}^{-1}\right]$. In this study, it was made dependent on the individual's physiology, as also explored in other works Bruse (2007); Havenith (2001). Dependence of body tissues conductance on the skin tissue average thickness was computed as following equivalent conductance:

$$
\frac{1}{U_{\text {c-sk }}}=\frac{1}{U_{\text {fat }+ \text { skin }}}+\frac{1}{U_{\text {muscle }}}
$$

With

$$
\begin{aligned}
U_{\text {muscle }} & =\left(\frac{0.05}{1+\frac{M-65}{130}}\right)^{-1}\left[\mathrm{~W} \cdot \mathrm{m}^{-2} \cdot \mathrm{K}^{-1}\right] \\
U_{\text {fat }+ \text { skin }} & =\left(\left(0.5 \times \overline{e_{\mathrm{sk}}}-2\right) \times 0.0048+0.0044\right)^{-1}\left[\mathrm{~W} \cdot \mathrm{m}^{-2} \cdot \mathrm{K} \text { (14 }\right)
\end{aligned}
$$

where $\overline{e_{s k}}[\mathrm{~mm}]$ is the average of skinfold thickness $e_{k}$ measured at 7 sites:

$$
\overline{\mathrm{e}_{\mathrm{sk}}}=\frac{1}{7} \times\left(\sum_{\mathrm{k}=1}^{7} \mathrm{e}_{\mathrm{k}}\right) \quad[\mathrm{mm}]
$$

The Jackson and Pollock's equation of body density $\rho$ provides a relationship between $\rho\left[\mathrm{kg} . \mathrm{m}^{-3}\right]$ and $\overline{e_{s k}}$ :

$$
\rho=\mathrm{C}-\mathrm{B} \times \overline{\mathrm{e}_{\mathrm{sk}}}+\mathrm{A} \times{\overline{\mathrm{e}_{\mathrm{sk}}}}^{2}
$$

where $\mathrm{A}=5,5.10^{-7} \quad, \quad \mathrm{~B}=4.3499 .10^{-4}$, $\mathrm{C}=1.1125075$ and $\mathrm{D}=2.8826 .10^{-4}$ for both men an women.

Equation (16) can hence be solved for $\overline{e_{s k}}$, provided the body density is known. The latter was derived from the relationship by Siri (1993):

$$
\rho=\left(\frac{\beta+4.5}{4.95}\right)^{-1} \quad\left[\mathrm{~kg} \cdot \mathrm{m}^{-3}\right]
$$

The resulting distribution of $U_{\text {c-sk }}$ (Figure $2 \mathrm{a}$ ), ranges from $\sim 6-15\left[\mathrm{~W} \cdot \mathrm{m}^{-2} \cdot \mathrm{K}^{-1}\right]$.

Values reported in literature range between $U_{T}=$ 8.3-33.3 [W.m $\left.{ }^{-2} \cdot \mathrm{K}^{-1}\right]$ Schweiker et al. (2017). However these published values relate to both the contribution of body tissues conductance and blood flowrelated heat transfer.

Values obtained for $\overline{e_{s k}}$ (Figure $2 \mathrm{~b}$ ) compare well to the measurements of Durnin and Womersley (1974) 

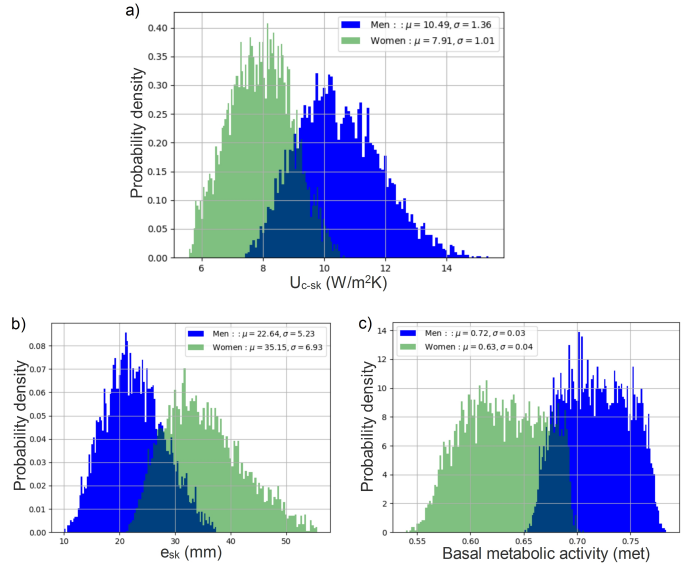

Figure 2: Individual physiological characteristics distributions for the French population ( $n=10$ 000) a) $U_{c-s k}$ b) Mean skinfold thickness $\overline{\mathrm{e}}_{\mathrm{sk}}$ c) Basal metabolic rate derived from Mifflin et al. (1990) for indoor activity.

who reported the sum of individuals' skinfold thickness, the average rangeing between $\sim 10$ and $\sim 45$ $[\mathrm{mm}]$ - both male and female.

Set value of the skin blood flow ( $q_{b}^{\text {set }}$ )

In the original model, the reference blood flow is calculated after Equation (5). However, the blood flow rate $q_{b}$ can be linearly corrected with the cardiac output factor (COF) Davoodi et al. (2018) as:

$$
C O F=\frac{C O}{C O_{\text {ref }}}
$$

where $C O_{\text {ref }}$ and $C O$ are respectively the cardiac outputs for the reference individual and the actual individual, calculated after Taylor et al. (1952):

$C O=0.061 \times m\left(1-\frac{\beta}{100}\right)+0.034 \times 100 \times h-4.313[\mathrm{~L} / \mathrm{min}]$

The reference individual is a 40 year old European male, weighing 73.5 [kg], and 1.71 [m] tall van Marken Lichtenbelt et al. (2007); ASHRAE (2009). COF then applies to the blood flow Equation (5) as well as the maximum blood flow rate.

Dilation, striction, sweating $\mathscr{6}$ shivering coefficients Different values can be found in the literature for the model coefficients $C_{d}, C_{s t}, C_{s w}$ and $C_{s h}$ :

- Dilation coefficient $C_{\mathrm{d}}$ : references Doherty and Arens (1988); Gagge et al. (1986) propose $C_{\mathrm{d}}=$ 200, whereas in Höppe (1993) the preferred value is $C_{\mathrm{d}}=75$ and ASHRAE (2013) provides a value of $C_{\mathrm{d}}=120\left[\mathrm{~L} \cdot \mathrm{m}^{-2} \cdot \mathrm{h}^{-1} \cdot \mathrm{K}^{-1}\right]$.

- References regarding the striction coefficient $C_{\mathrm{st}}$ ASHRAE (2013); Gagge et al. (1971) agree on $C_{\mathrm{st}}=0.5\left[\mathrm{~K}^{-1}\right]$.
- Reference values for sweating $C_{\mathrm{sw}}$ and shivering $C_{\text {sh }}$ coefficients were taken as per the original model, $170\left[\mathrm{~g} \cdot \mathrm{m}^{-2} \cdot \mathrm{h}^{-1}\right]$ and $19.4\left[\mathrm{~W} \cdot \mathrm{m}^{-2} \cdot \mathrm{K}^{-2}\right]$.

As these model coefficients cannot be measured directly, we implement here the approach used by Davoodi et al. (2018), introducing a dependency between body surface and blood flow or sweating rate.

$$
C F A=\frac{A}{A_{\text {ref }}}
$$

where $A_{\text {ref }}$ is the Dubois body surface area of the reference individual. CFA applies to Equations (5), (6) and (7).

With 14 variable parameters in the model, a sufficient number of evaluations is required. The number of individuals was hence increased until both average value and standard deviation stabilized under various conditions, which occurred for $\sim 10000$ samples.

\section{Limitations of the method}

Individual adaptation, such as adapting the clothing level based on preferred temperatures, and acclimatization or fitness of individuals were not considered.

The correlations established for the breathing heat loss were not modified as their influence was considered as limited.

BMI distribution was not defined per age groups, the hypothesis being that it remained the same for all of them. This assumption may easily be challenged.

The skin blood flow equation (5) has not been modified in order to best fit the original model, though others were found in the literature.

\section{Results}

The standard deviation of $\mathrm{SET}^{*}$ is presented on psychrometric charts for four different conditions.

\section{Psychrometric charts}

The average $\mathrm{SET}^{*}$ and its standard deviation were computed on psychrometric charts for different air velocity conditions and mean radiant temperatures. For each point on the charts presented in Figure 3, 10000 random drawings were performed. The standard deviation related to the variations among individuals of both sexes was calculated for each of the series of SET $^{*}$ obtained, an equal number of individuals being drawn for each sex.

Four types of conditions were studied on the psychrometric chart for relative humidities ranging from 0 to 100\%:

- Operative temperature: equal air and radiant temperatures $\left(T_{a}=T_{r}\right)$

- High mean radiant temperature (MRT): radiant temperature $30[\mathrm{~K}]$ higher than the air temperature ( $i d$ est for each abscissa : $T_{r}=T_{a}+30$ ), simulating high solar irradiation 
- Wind: operative temperature with $0.7[\mathrm{~m} / \mathrm{s}]$ air velocity

- High mean radiant temperature and wind: high MRT with $0.7[\mathrm{~m} / \mathrm{s}]$ air velocity

\section{Operative temperature conditions}

Operative conditions studied corresponded to: $T_{a}=$ $T_{r}$ and $\mathrm{v}=0.1 \mathrm{~m} \cdot \mathrm{s}^{-1}$. Results presented in Figure 3 a) show the standard deviation $\sigma_{S E T^{*}}\left[{ }^{\circ} \mathrm{C}\right]$. For these conditions, $\sigma_{S E T^{*}} \in[0.25,0.9]$.

Even under ideal temperature and humidity conditions (in the vicinity of $19-25\left[{ }^{\circ} \mathrm{C}\right], 50[\%]$ relative humidity) variability amongst individuals has an influence on evaluation of comfort through the model. The standard deviation reaches $\sigma_{S E T^{*}} \sim 0.35-0.5\left[{ }^{\circ} \mathrm{C}\right]$. This could allow $\mathrm{SET}^{*}$ to get out of the 22.2-25.6 $\left[{ }^{\circ} \mathrm{C}\right]$ comfort zone of the original model for at least a part of the population when the average $\mathrm{SET}^{*}$ reaches the edge of these bounds (the proportion of which will be examined further in this paper). This is in line with the findings that examining a wide group of building occupants, it was seen that they do not have a predilection for narrowly controlled indoor temperatures Arens et al. (2010).

The winter conditions $\left(\mathrm{T}_{\mathrm{a}}=0-10\left[{ }^{\circ} \mathrm{C}\right]\right)$ exhibit a significant standard deviation $\left(\sigma_{S E T^{*}} \sim 0.7-0.9\left[{ }^{\circ} \mathrm{C}\right]\right)$, hence indicating a diverse physiological reponse under low temperatures conditions.

The standard deviations under high temperatures are the lowest $\left(\sigma \sim 0.25-0.35\left[{ }^{\circ} \mathrm{C}\right]\right)$. From a thermal comfort point of view, the population behaves more homogeneously under hot conditions than under cold conditions. This relates at least partly to skin blood vessels being dilated under warm conditions, leading to a more uniform skin temperature.

\section{High mean radiant temperature conditions}

The $\sigma_{S E T^{*}} \in[0.1,0.5]$ (Figure $3 \mathrm{~b}$ ) is smaller than those for operative conditions. The oblique yellow zone on the chart corresponds to the split between individuals having reached critical skin wettedness or not (for concision reasons this point will not be adressed here). Beyond this zone, the entire population has reached critical sudation and $\sigma_{S E T^{*}}$ decreases. Air temperatures around $0^{\circ} \mathrm{C}$ also exhibit a higher variability.

\section{Windy conditions}

Interestingly, in windy conditions, Figure $3 \mathrm{c}$ ), the standard deviation resembles that of operative conditions, $\sigma_{S E T^{*}} \in[0.15,1.0]$, meaning the population studied with the model shows a rather homogenous dispersion of $\mathrm{SET}^{*}$ around the average for both windy and windless conditions (the average SET ${ }^{\mathrm{v}}$ alues being lower for windy conditions).

\section{High mean radiant temperature and windy} conditions

In windy, high mean radiant temperature conditions, according to Figure $3 \mathrm{~d}$ ), the standard deviation is:
$\sigma_{S E T^{*}} \in[0.1,0.6]$. Wind changes the threshold for critical skin wettedness occurrence. Compared to Figure $3 \mathrm{~b}$ ), the increased variability zone (oblique yellow zone) shifted to the right, implying that when windy, critical sudation was reached at warmer temperature.

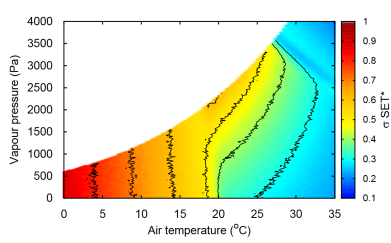

(a) Windless conditions

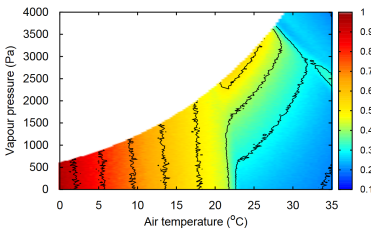

(c) Windy conditions

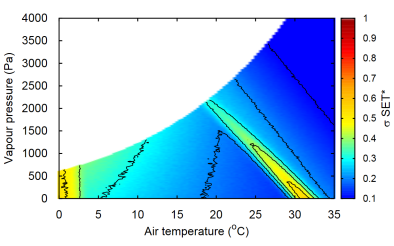

(b) High MRT conditions

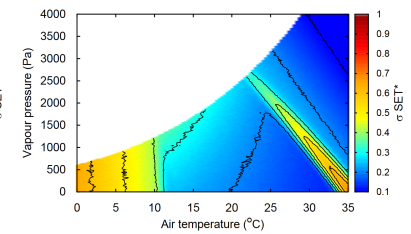

(d) High MRT + wind
Figure 3: Standard deviation for high mean radiant temperature and windy conditions with iso- $\sigma_{S E T^{*}}$ values every $0.1[K]$.

The literature review by Van Hoof (2008) quotes preferred temperature ranges in various field studies varying from a few degrees to $\sim 10[\mathrm{~K}]$ and standard deviations of 1 to $2[\mathrm{~K}]$. Such a range is noticeably higher than the results presented here. Thermal comfort sensation can be due to factors other than the physical, thermal environment. The current work did not take into consideration variability of clothing and other behavioural or psychological adjustments among the population. This study presents the physiological aspects of variability over a population, which would be complemented by behavioural and psychological aspects. Nevertheless, the physiological component of variability does exist.

\section{Percentage of individuals within comfort zone}

The $\mathrm{SET}^{*}$ comfort range, between 22.2 and $25.6^{\circ} \mathrm{C}$, is taken from Nishi and Gagge (1977) and represents $\sim 80 \%$ individuals satisfied with indoor conditions. Using mean and standard deviation of SET ${ }^{*}$ obtained in Section for indoor operative temperature conditions (Figure $3 \mathrm{a}$ ), the percentage of individuals within comfort was computed by integrating the analytical Gaussian distributions. For the values between $-\infty$ and $x$, with $x=22.2$, this percentage is:

$F(x)=\int_{-\infty}^{x} \frac{1}{\sqrt{2 \pi} \sigma} e^{\frac{-(x-\mu)^{2}}{2 \sigma^{2}}} d x=\frac{1}{2}\left(1+\operatorname{erf}\left(\frac{x-\mu}{\sigma \sqrt{2}}\right)\right)$

The "right hand side" of integral $F(x)$, i.e., the percentage of a distribution beyond the upper limit of the comfortable $\mathrm{SET}^{*}(x=25.6)$, may be calculated 
similarly.

On the warmer side of the comfort zone, i.e., SET ${ }^{*}$ $=25.6^{\circ} \mathrm{C}$, the 10,80 and $95 \%$ isopercentages lines of comfortable individuals are in a relatively narrow range (Figure 4). The dashed lines for $95 \%$ and $80 \%$ lay on both sides of the $25.6^{\circ} \mathrm{C} \mathrm{SET}{ }^{*}$ limit. Comfort percentage rapidly drops as this limit is passed.

In the vicinity of the cooler threshold of the comfort zone, the percentage of comfortable people is spread wider. One can see on Figure 4 that the $95 \%$ limit stands within the generally accepted $\mathrm{SET}^{*}$ comfort zone. At the lower limit of the comfortable SET*, $50 \%$ of the studied population is outside the comfort range (the $50 \%$ line and the $22.2^{\circ} \mathrm{C} \mathrm{SET}^{*}$ actually coincide). The behaviour observed in Figure 4 suggests

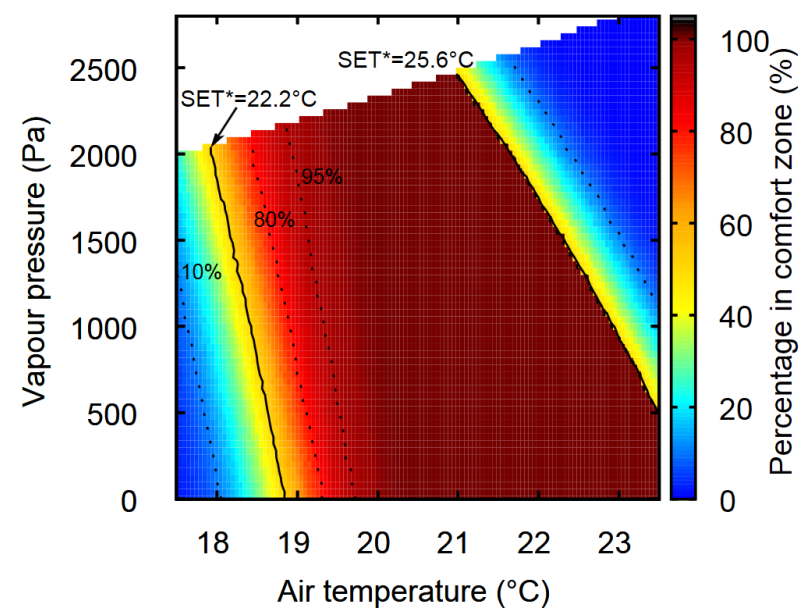

Figure 4: Percentage of individuals within the comfort zone in windless, operative temperature conditions (solid lines : SET limit values for comfort, dashed lines : isopercentages 10, 80 and 95\%).

a narrower comfort zone, after the SET ${ }^{*}$ model: a similar upper bound but a $0.5[\mathrm{~K}]$ greater lower bound for $80 \%$ acceptability, i.e. $22.7^{\circ} \mathrm{C}$. Beyond the limits of comfort, on both warm and cool side, comfort percentages rapidly drop off, similar to findings from analysis of field study data Zhang et al. (2011). The 80 and $90 \%$ comfort lines are much closer on the warm side than on the cool side. We hypothesize this asymmetry originates from a more homogeneous vasodilation under warm conditions Huizenga et al. (2004), leading to more consistency in perception. Deviation of the $\mathrm{SET}^{*}$ lower comfort limit (22.2 to 22.7 ), compared to PMV evaluations, could be interpreted in the light of the recent compilation of worldwide field studies, ASHRAE Database II Földváry et al. (2018), where the percentage satisfaction-thermal sensation vote curve also shows a slight asymmetry with the minima not being on the neutral point of the thermal sensation scale but slightly to the warmer side.

\section{Sensitivity analysis}

Complementing the study of physiological variability, a sensitivity analysis of the $\mathrm{SET}^{*}$ model was conducted. Morris' method Morris (1991) using the Python SALib package Herman and Usher (2017) was chosen. The method's principle is briefly described here, however a thorough explanation can be found in Saltelli et al. (2008). It relies on the computation of the elementary effect $E E_{k}$ related to parameter $x_{k}$ on the output using a finite difference between two SET $^{*}$ calculations, changing one parameter $x_{k}$ at a time. This evaluation is repeated a number of times $r$ and the average $\mu_{k}$ of all elementary effects $E E_{k}$ for parameter $x_{k}$ is computed:

$$
\mu_{k}=\frac{1}{r} \sum_{i=1}^{r}\left|E E_{k}^{i}\right|
$$

The standard deviation of the series of elementary effect $\sigma_{k}$ is also computed.

The importance of each parameter, $x_{k}$, on the $\mathrm{SET}^{*}$ is evaluated by plotting the average elementary effect $\mu_{k}$ against the standard deviation $\sigma_{k}$. Parameters' ranking is determined by the ratio of magnitudes of the computed average and standard deviation. There are roughly two types of influences:

- Linear influence of a parameter: characterized by points below the first bisector.

- Non-linear influence of a parameter: characterized by a position above the first bisector: the dispersion of the distribution is of the same order or above the elementary effect, meaning there could be an interaction with other parameters.

Results presented are for $20\left[{ }^{\circ} \mathrm{C}\right]$ air and radiant temperatures, $50[\%]$ relative humidity and $0.1[\mathrm{~m} / \mathrm{s}]$ air velocity $(\mathrm{n}=10000)$. Various conditions were tested and yielded similar results.

Figure $5 \mathrm{a}$ and $5 \mathrm{~b}$ show that age has a linear influence on $\mathrm{SET}^{*}$, is the predominant factor for both sexes. Age affects several key parameters - metabolic activity according to the Mifflin equation (4), body fat percentage according to the Deurenberg equation (11), and cardiac output equation (19) - consequently impacting the model results. However, it may be added here that the results of the simulations, that find a significant impact of age, may not translate well to the findings from field studies. The limitation lies in how the impact of age is factored into the model. More accurate models of the future may not have this shortcoming and would benefit better from the analysis scheme presented in this work.

Height is the second most influential parameter for women, while BMI comes second for men. Both parameters have a large span of variation across individuals, explaining their ranks. They also affect the calculation of mass and body surface area, Equations (10) and (3), which stand for the inertial terms in the differential equations solved for skin and core temperature (1) and (2).

Interestingly, corpulence parameters (height and 
$\mathrm{BMI})$ have more influence on the average $\mathrm{SET}^{*}$ for women than for men: respectively $\sigma \sim 0.25$ versus $\sigma \sim 0.9$ and also $\sigma / \mu * \sim 0.5$ for women and $\sigma / \mu * \sim 1$ for men. These parameters induce a non-linear behaviour, or may have interactions with other parameters for men. For men, height was fourth, behind the skin set temperature.

For both sexes, skin and core set temperatures' elementary effects are such that $\sigma / \mu * \sim 0.5$, meaning the model behaves monotonously with the evolution of these parameters. Similarly to these results, a recent field study showed that sex, age, and BMI have a significant impact on the deviations from neutral conditions occupants can be comfortable with Rupp et al. (2018).

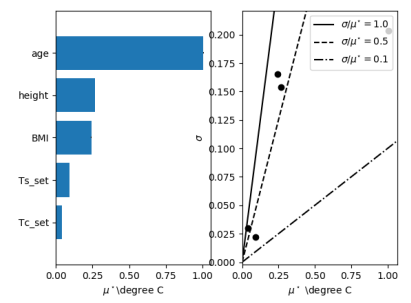

(a)

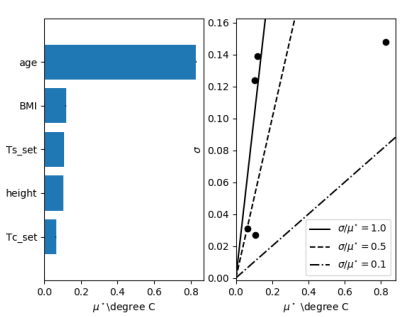

(b)
Figure 5: Sensitivity analysis after Morris' method for a) women and b) men.

To conclude, the most influential parameters on the variability for the $\mathrm{SET}^{*}$ model are sex and age. The corpulence parameters (height and BMI) come next for women, whereas for men the BMI and skin set temperature are in second and third position (height comes shortly after).

\section{Conclusion}

This work explored the effect of physiological variability on $\mathrm{SET}^{*}$, using the original governing equations of human physiology by Gagge et al. (1971, 1986). Implementing state-of-the-art computation of thermophysiological parameters, individual variability sex, age, and body morphology — was accounted for by studying not a virtual reference individual, but the French population. The SET ${ }^{*}$ comfort index was computed using random drawing of samples of 10 000 individuals combined with probability distribution functions.

Around comfort zone, for $\mathrm{SET}^{*}$ values between 22.2 and $25.6\left[{ }^{\circ} \mathrm{C}\right]$, the standard deviation reaches $\sim 0.7$ $[\mathrm{K}]$. For the $\mathrm{SET}^{*}$ values near those upper and lower bounds, usually close to ideal indoor conditions, a significant part of the population can be dissatisfied. Indeed, if the model predictions are correct, the SET $^{*}$ lower bound for $80 \%$ acceptability, should be increased by $0.5[\mathrm{~K}]$ for the population studied.

The standard deviation of the SET ${ }^{*}$ increases when temperature decreases, implying that the $\mathrm{SET}^{*}$ ex- perienced by individuals is more spread-out in cold environments.

The sensitivity analysis revealed that, as examined from the two-node model, sex and age are the most influential parameters on the $\mathrm{SET}^{*}$ and female individuals exhibit more individual variability.

\section{References}

Arens, E., M. A. Humphreys, R. de Dear, and H. Zhang (2010). Are 'class a'temperature requirements realistic or desirable? Building and Environment 45(1), 4-10.

ASHRAE (edited by) (2009). ASHRAE Handbook Fundamentals - Chapter 9: Thermal comfort (Inch-Pound ed.). American Society of Heating, Refrigerating and Air-Conditioning Engineers.

ASHRAE (2013). Thermal Environmental Conditions for Human Occupancy. ANSI/ASHRAE addendum $b$ to ANSI/ASHRAE Standard 55-2013, $1-14$.

Bruse, M. (2007). Multi-Agent Systems - A new approach for assessing urban environmental conditions. Habilitation thesis, Ruhr-Universität Bochum.

Chudecka, M., A. Lubkowska, and A. KempińskaPodhorodecka (2014). Body surface temperature distribution in relation to body composition in obese women. Journal of Thermal Biology 43, 1-6.

Davoodi, F., H. Hassanzadeh, S. A. Zolfaghari, G. Havenith, and M. Maerefat (2018). A new individualized thermoregulatory bio-heat model for evaluating the effects of personal characteristics on human body thermal response. Building and Environment $136,62-76$.

de Saint Pol, T. (2007). L'obésité en france : les écarts entre catégories sociales s'accroissent.

Deurenberg, P., J. A. Weststrate, and J. C. Seidell (1991). Body mass index as a measure of body fatness: age-and sex-specific prediction formulas. British journal of nutrition 65(2), 105-114.

Doherty, T. J. and E. A. Arens (1988). Evaluation of the physiological bases of thermal comfort models. ASHRAE Transactions 94(1), 1371-1385.

Duclos, J.-Y., J. Leblanc, and D. E. Sahn (2011). Comparing population distributions from binaggregated sample data: An application to historical height data from france. Economics 8 Human Biology 9(4), 419-437.

Durnin, J. V. and J. Womersley (1974). Body fat assessed from total body density and its estimation from skinfold thickness: measurements on 481 men and women aged from 16 to 72 years. British journal of nutrition 32(1), 77-97. 
Földváry, V., T. Cheung, H. Zhang, R. de Dear, T. Parkinson, E. Arens, C. Chun, S. Schiavon, M. Luo, G. Brager, et al. (2018). Development of the ashrae global thermal comfort database ii. Building and Environment.

Gagge, A., A. Fobelets, and L. Berglund (1986). A standard predictive index of human response to the thermal environment. ASHRAE Transactions 14, 709-731.

Gagge, A., J. Stolwijk, and Y. Nishi (1971). An effective temperature scale based on a simple model of human physiological regulatory response. ASHRAE Transactions 77, 21-36.

Havenith, G. (2001). Individualized model of human thermoregulation for the simulation of heat stress response. Journal of Applied Physiology 90, 19431954.

Herman, J. and W. Usher (2017, jan). SALib: An open-source python library for sensitivity analysis. The Journal of Open Source Software 2(9).

Höppe, P. (1993). Heat Balance Modelling. Experientia, 741-746.

Huizenga, C., H. Zhang, E. Arens, and D. Wang (2004). Skin and core temperature response to partial-and whole-body heating and cooling. Journal of Thermal Biology 29(7-8), 549-558.

Koepke, N., J. Floris, C. Pfister, F. J. Rühli, and K. Staub (2018). Ladies first: Female and male adult height in switzerland, 1770-1930. Economics $\&$ Human Biology 29, 76-87.

Mackowiak, P. A., S. S. Wasserman, and M. M. Levine (1992). A critical appraisal of $98.6 \mathrm{f}$, the upper limit of the normal body temperature, and other legacies of carl reinhold august wunderlich. Jama 268(12), 1578-1580.

Mifflin, M. D., S. T. St Jeor, L. A. Hill, B. J. Scott, S. A. Daugherty, and Y. O. Koh (1990). A new predictive equation for resting energy expenditure in healthy individuals. The American journal of clinical nutrition 51(2), 241-247.

Morris, M. D. (1991). Factorial sampling plans for preliminary computational experiments. Technometrics 33(2), 161-174.

Nishi, Y. and A. Gagge (1977). Effective temperature scale useful for hypo-and hyperbaric environments. Aviation Space and Environmental Medicine 48(2), 97-107.

Pasco, J. A., G. C. Nicholson, S. L. Brennan, and M. A. Kotowicz (2012). Prevalence of obesity and the relationship between the body mass index and body fat: cross-sectional, population-based data. PloS one 7(1), e29580.
Pickup, J., R. de Dear, et al. (2000). An outdoor thermal comfort index (out_set*)-part i-the model and its assumptions. In Biometeorology and urban climatology at the turn of the millenium. Selected papers from the Conference ICB-ICUC, Volume 99, pp. 279-283.

Ranasinghe, C., P. Gamage, P. Katulanda, N. Andraweera, S. Thilakarathne, and P. Tharanga (2013). Relationship between body mass index (bmi) and body fat percentage, estimated by bioelectrical impedance, in a group of sri lankan adults: a cross sectional study. $B M C$ Public Health 13(1), 797.

Rupp, R. F., J. Kim, R. de Dear, and E. Ghisi (2018). Associations of occupant demographics, thermal history and obesity variables with their thermal comfort in air-conditioned and mixed-mode ventilation office buildings. Building and Environment 135, 1-9.

Saltelli, A., M. Ratto, T. Andres, F. Campolongo, J. Cariboni, D. Gatelli, M. Saisana, and S. Tarantola (2008). Global sensitivity analysis: the primer. John Wiley \& Sons.

Schweiker, M., B. Kingma, and A. Wagner (2017). Evaluating the performance of thermal sensation prediction with a biophysical model. Indoor Air.

Siri, W. (1993). Body composition from fluid spaces and density: analysis of methods. 1961. Nutrition (Burbank, Los Angeles County, Calif.) 9(5), 480.

Takada, S., T. Sakiyama, and T. Matsushita (2011). Validity of the two-node model for predicting steady-state skin temperature. Building and Environment 46(3), 597-604.

Taylor, H. L., J. Brozek, A. Keys, and W. Carlson (1952). Basal cardiac function and body composition with special reference to obesity. The Journal of clinical investigation 31(11), 976-983.

Van Hoof, J. (2008). Forty years of fanger's model of thermal comfort: comfort for all? Indoor air 18(3), 182-201.

van Marken Lichtenbelt, W. D., A. J. Frijns, M. J. van Ooijen, D. Fiala, A. M. Kester, and A. A. van Steenhoven (2007). Validation of an individualised model of human thermoregulation for predicting responses to cold air. International Journal of Biometeorology 51(3), 169-179.

Zhang, H., E. Arens, and W. Pasut (2011). Air temperature thresholds for indoor comfort and perceived air quality. Building Research \& Information 39(2), 134-144.

Zhou, X., H. Zhang, Z. Lian, and Y. Zhang (2014). A model for predicting thermal sensation of chinese people. Building and Environment 82, 237-246. 